\title{
Microbial Diagnosis in Periodontics: Merits and Demerits: A Review
}

\author{
Dr. K. Malathi ${ }^{1}$, Dr. K. Sharmila ${ }^{2}$, Dr. Dhanesh Sable ${ }^{3}$, Dr. Shabbir Ahamed ${ }^{4}$ \\ (Department Of Periodontics, Tamil Nadu Govt. Dental College, Chennai)
}

\begin{abstract}
Oral microbiology plays a major role not only in etiology but also our ability to prevent and treat oral diseases. Rapid and specific tests to identify the bacteria have facilitated increased testing by clinicians. However, results must be interpreted with regard to current concepts of etiology and pathogenesis of periodontal diseases. Various techniques/methods have been described for microbial diagnosis. This paper addresses the different microbiological diagnostic aids and their short comings.
\end{abstract}

Key Words:Microbial analysis, diagnostic aids, merits and demerits.

\section{Introduction:}

Epidemiological surveys have shown that most of the adults present some mild form of periodontal disease. 5 to $15 \%$ of them suffer from severe periodontitis ${ }^{7}$. Periodontitis is mostly associated with microorganism colonizing on the tooth surface and that is the main reason for prevention of periodontal disease is mainly based on plaque control. Even after following preventive practice on periodontitis, controlling the periodontal disease still remains a major public health problem in general population. Treatment is usually initiated when lesions are clinically detectable and tissue damage is irreversible. This occurs mainly due to the lack of diagnostic methods to detect early tissue change when the lesions are still at a reversible stage and can be treated in a non-invasive way. The treatment should be targeted at controlling the etiological agents.

Various techniques/ methods have been described for microbial diagnosis. Some of the diagnostic tests includesCulture Methods, Direct Microscopy, Immunofluorescence Method, ELISA test, BANA test, Polymerase Chain Reaction, DNA probe, Checker Board DNA-DNA - hybridization technique, Restriction Endonuclease Analysis and Microbiological kits etc. In this article the merits and demerits of different microbiological aids are discussed.

\section{CULTURE METHODS ARE OF TWO TYPES}

\section{Culture Methods ${ }^{4,5}$}

\section{$>$ AEROBIC CULTURE METHODS \\ Merits $^{1}$ \\ ANAEROBIC CULTURE METHODS}

- $\quad$ Culture methods are valuable as research tools to study micro-organisms associated with periodontal diseases.

- $\quad$ They can obtain relative and absolute count of cultivable species and able to access for antibiotic susceptibility of microbes.

- $\quad$ They can detects broad spectrum of bacteria in a sample and are considered as the GOLD STANDARD

TEST

Demerits

- They require high degree of expertise. They are difficult to perform and are highly technique sensitive.

- $\quad$ Culture methods are time consuming procedures, expensive and can only grow live bacteria. Sampling and transparent conditions are essential.

- $\quad$ Proper equipment's are needed.

- $\quad$ They show decreased sensitivity and specificity.

- The putative pathogens such as Treponema species and bacteriodes cannot be cultured.

- In culture methods, multiple source of error can occur.

\section{Direct Examination ${ }^{5}$ :}

Direct examination can be done by Light Microscopy and Dark Field Microscopy.

Merits

- Microscopic techniques are quick and easy.

- It is an inexpensive means of smearing a microbial sample for major morphotypes.

- The assessment can be done during the progression and treatment of the disease. 
- In microscopy, bacterial shape, size and mobility can be detected.

- The bacteria associated with health and disease can be detected.

- They also detect the microbial shift.

\section{Demerits}

- There is an inability to identify certain species and distinguish individual bacterial species.

- $\quad$ The species have to be examined as soon as they are collected from the patient.

- In this technique, there is an inability to differentiate among the various species of Treponemas.

- $\quad$ They cannot be used as a diagnostic test for destructive periodontal disease 2 .

\section{DNA PROBES ${ }^{4}$ :}

\section{Merits}

- $\quad$ DNA probes are very specific and are used to determine phenotypic markers.

- It has great specificity and sensitivity. They are not affected by transport conditions.

- $\quad$ They do not require anaerobic conditions to be maintained.

- $\quad$ They can be done in dead bacteria and they do not depend on bacterial viability.

\section{Demerits}

- $\quad$ They are very expensive.

- $\quad$ The minimal detection limits are 103 to 105 cells of particular species.

- The chair side diagnosis is not possible.

- The cross reactivity by oligonucleotide probes can occur.

- $\quad$ Antibiotic sensitivity is not possible.

\section{POLYMERASE CHAIN REACTION ${ }^{12}$ :}

Merits

- $\quad$ PCR is a quick reliable method.

- The technique permits replication and multiplication of the number of target DNA or RNA fragment present in a sample (target to specific microorganism).

- $\quad$ The quantitative data of DNA can be obtained in a simplified manner.

- $\quad$ It is a powerful tool used to identify unknown organisms.

- They are used for tiny amounts of HIDV and numerous genetic anomalies.

- $\quad$ Several samples can be tested simultaneously.

- They have greater sensitivity and specificity and they don't require anaerobic conditions to be maintained during sampling.

- They are not affected by transport conditions.

- $\quad$ Helpful to study DNA and RNA obtained from variety of tissue sources

\section{Demerits}

- $\quad$ PCR cannot be used for diagnostic or prognostic purposes.

- $\quad$ They provide information about the prevalence of the tested bacterium.

- $\quad$ They cannot differentiate between viable and non-viable organisms.

- $\quad$ They cannot be used to monitor responses to therapy.

- They are useful only when the sequences of proteins to be detected are already known.

- Unable to quantify the pathogens accurately in clinical samples.

- $\quad$ They require extensive instrumentation and definite lab test is needed.

- $\quad$ They are also very expensive

\section{IMMUNOFLUORESCENT METHODS ${ }^{4}$ :}

Immunofluorecent methods are used to detect bacterial species that are genetically distinct. They help in identifying target bacteria.

They are of two types

\section{DIRECT IMMUNOFLUORESCENCE}

$>$ INDIRECT IMMUNOFLUORECENCE

Merits

- Immunofluorecent methods identify dead target cells and they don't require stringent sample and transport media.

- $\quad$ They don't require viable cells.

\section{Demerits}

- In this technique, local sampling cannot be done. The site specific parameter cannot be assessed. 
- $\quad$ The bacterial virulence cannot be determined.

- They cannot determine the antibiotic susceptibility.

Merits

$$
\mathbf{E L I S A}^{3,4} \text { : }
$$

- $\quad$ ELISA is the widely accepted method.

- The reagents are stable and cheap.

- $\quad$ The procedure is simple and sensitive.

- It is easy to understand and perform.

- It is as sensitive as immunoassay.

- $\quad$ It can be used to monitor antibody levels (up to 2.3 to 4.67 titers)

Demerits

- $\quad$ In this procedure, not all the patients affected with microbes demonstrate increased Ig level.

- Some organisms causing periodontitis either do not induce or may suppress immune reaction.

- Used to identify volatile sulphur compounds in halitosis patients

Demerits

- In this test, there is always a lack of quantitative data.

- The specific bacteria that are responsible for enzyme production can't be determined.

- They cannot identify the presence of other pathogens that do not produce trypsin like enzyme.

- The results are qualitative and rely upon the operator's assessment at the calorimetric end point.

Merits

CHECKER BOARD DNA-DNA HYBRIDIZATION TECHNOLOGY ${ }^{3,6,13}$ :

- In this technique, the rapid processing of large no.of plaque sample is done and they help in identification of multiple bacterial species.

- They are highly specific and they don't need bacterial viability. They are used for epidemiological research and ecologic studies.

\section{Demerits}

- $\quad$ They need sophisticated lab equipment's and high expertise is needed for diagnostic purposes.

- They are highly specific and so they are not used for diagnostic purposes.

- The detection limit can be 80 and approximates up to 1000 cells.

- It is not applicable for use with a single subgingival plaque.

- It does not provide an estimate of the total bacterial mass in the specific site.

\section{Restriction Endonuclease Analysis:}

- Restriction endonuclease analysis is a powerful tool for detecting the distribution of a specific pathogenic strain throughout the population.

- $\quad$ They are used in molecular genetic analysis of oral bacteria like Pg, Aa, Pi, Ec and Td.

- $\quad$ They help in studying the transmission patterns of putative periodontal pathogens among family members.

\section{Microbial Test Kits: ONNIGENE ${ }^{1}$}

Merits

- $\quad$ Reports are provided within short periods of time, few hours to few days.

- It helps in identification of number of known periodontal pathogen

Merits

\section{EVALUSITE ${ }^{8}$ :}

- It employes a normal membrane base enzyme immunoesaay for the detection of three putative periodonto pathogens. (Aa, $\mathrm{Pg}, \mathrm{Pi}$ ). 


\section{Demerits}

- It is multistage test.

- It has a subjective calorimetric end point.

- $\quad$ There is no permanent record of the result.

- Gives the assumption that the three organism are causing the disease

\section{Conclusion:}

Microbiological tests have the potential to support the diagnosis of various forms of periodontal diseases. Microbial tests can also be used to monitor periodontal therapy directed towards the suppression and eradication of periodontal pathogenic organisms. The difficulty in all microbiological tests is that it is likely a range of interacting bacteria is capable of causing disease; the combination may differ between individuals ${ }^{6}$. The tests directed at individual species may be too specific and may not account for different clonal types.

\section{References:}

[1] Carranza's Clinical Periodontology, 9th Edition, newman, Advanced Diagnostic techniques- advances in microbiological analysis. Chapter 34, 495-498.

[2] Carranza's Clinical Periodontology, $10^{\text {th }}$ edition, Advanced Diagnostic techniques- advances in microbiological analysis, chapter 37, 587-594.

[3] Carranza's Clinical Periodontology, $11^{\text {th }}$ edition Advanced Diagnostic techniques- advances in microbiological analysis, chapter 37 , 1353-1359.

[4] Essential of periodontology, Sahitya Reddy S, microbiological diagnostic aids in periodontology, chapter-46, page 467-474

[5] Text book of Periodontology and Oral Implantology, DrAshitaUppoor, DrDilip G Nayak, Dr Mahesh C.P, advanced diagnostic methods, aids in microbiological diagnosis, page 255, chapter 32

[6] Luciana M. Shaddox, Clay Walker, Microbial testing in periodontics: value, limitations and future directions, Periodontology 2000, Volume 50, Issue 1, pages 25-38, June 2009.

[7] Potential of Diagnostic Microbiology for Treatment and Prognosis of Dental Caries and Periodontal Diseases, P.C. Baehni and B. Guggenheim, CROBM 1996 7: 259.

[8] Mikx FH, Renggli HH. How sensible are bacteriological tests in periodontology? Ned TijdschrTandheelkd. 1994 Dec;101(12):4848.

[9] Laughton B, Syned S, Loesche W. API ZYM system for identification of Bacteroides ssp., Capnocytophagia ssp., and spirochaetes of oral origin. J Clin Microbial 1982;15:97-127.

[10] Loesche W, Syed S, Stoll J. Trypsin-like activity in sub-gingival plaque: A diagnostic marker for spirochetes and periodontal disease? J Periodont 1987;58:266-273

[11] Ishihara K, Naito Y, Kato T, Takazoe I, Okuda K, Eguchi T, NakashimaK , Matsuda M, Yamasaki K, HasegawaK , Suido H, Sugihara K. A sensitive enzymatic method (SK- 013) for detection and quantification of specific periodontopathogens. J Periodont Res 1992; 27: 81-85.

[12] Hiroshi Masunaga; WataruTsutae et al. Use of quantitative PCR to evaluate methods of bacteria sampling in periodontal patients, ournal of Oral Science; VOL.52; NO.4; PAGE.615-621; (2010).

[13] Papapanou PN, Madianos PN, Dahlén G, Sandros J. "Checkerboard" versus culture: a comparison between two methods for identification of subgingival microbiota. Eur J Oral Sci. 1997 Oct;105(5 Pt 1):389-96. 